\title{
Production of 316L stainless steel implant materials by powder metallurgy and investigation of their wear properties
}

\author{
KURGAN Naci ${ }^{*}$, SUN Yavuz, CICEK Bunyamin \& AHLATCI Hayrettin \\ Engineering Faculty, Karabuk University, Karabuk 78050, Turkey \\ Received November 1, 2011; accepted December 22, 2011; published online March 8, 2012
}

In this study, the mechanical and wear properties of AISI 316L stainless steel implant materials, produced by powder metallurgy $(\mathrm{P} / \mathrm{M})$, were investigated. AISI 316L stainless steel powder was cold-pressed with $800 \mathrm{MPa}$ of pressure and then sintered at 1200, 1250 and $1300^{\circ} \mathrm{C}$ for $30 \mathrm{~min}$ as three sample groups. The microstructure, and mechanical and wear properties of the resulting steels were investigated. Light optical and scanning electron microscopiese were used to characterize the microstructure of the steels. Room temperature mechanical properties of the steels were determined by hardness measurements and impact tests. Wear was determined using the pin-on-disc wear test, and the results were evaluated according to weight loss. The results indicate that the sintering temperature, time and atmosphere are important parameters that affect the porous ratio of materials produced by P/M. Sintering at high temperature can eliminate small pores and make the residual pores spherical. The wear tests showed that the wear of the AISI 316L stainless steel implants changed depending on the sintering temperature and load. Spherical pores in the samples increase the wear resistance. Moreover, decreasing the porosity ratio of these materials improves all of their mechanical properties.

powder metallurgy, wear, 316L implant, mechanical properties

Citation: Kurgan N, Sun Y, Cicek B, et al. Production of 316L stainless steel implant materials by powder metallurgy and investigation of their wear properties. Chin Sci Bull, 2012, 57: 1873-1878, doi: 10.1007/s11434-012-5022-5

Implants have been used since 1660 for various purposes. Modern use of implants in dentistry and medicine began in 1960 [1]. Today many types of metallic and non metallic implants are used in the human body for different purposes. Artificial materials with appropriate physical, mechanical, chemical and electrical properties are often used in orthopedic applications [2]. A collective interdisciplinary study of implants including the fields of medicine, biology and some branches of bio engineering such as biomechanics and biomaterials science is required [3].

The first implants produced from metallic materials by powder metallurgy (P/M) date back to the 1960s when a porous hip prosthesis was produced from Co-Cr-Mo alloy. These studies aimed at improving the mechanical and physical properties of $\mathrm{P} / \mathrm{M}$ implants [4]. P/M processing methods have helped to improve surgical implants in the last

*Corresponding author (email: nkurgan@karabuk.edu.tr; kurgannaci@yahoo.com)
20-30 years. Implants produced by $\mathrm{P} / \mathrm{M}$ are specifically preferred in orthopedic and dentistry cases where a robust and reliable implant-bone connection and a high load bearing capacity are needed [5]. Implants that are produced by hot isostatic pressing of prealloyed powders can have ideal mechanical properties. In addition, $\mathrm{P} / \mathrm{M}$ can produce fine grain size, improve the homogeneity of the material, and allow the production of final size, high quality implants in a cost effective manner [6]. P/M has been used to improve the microstructure and mechanical properties of implants as well as avoid possible casting defects [7].

Stainless steels produced by P/M play an important role in the machine industry because of their low production cost and reduced need for part processing. In current industrial processes, P/M stainless steels have a specific mass of $7.0-7.1 \mathrm{~g} / \mathrm{cm}^{3}$ while the theoretical specific mass of stainless steels today is about $7.9 \mathrm{~g} / \mathrm{cm}^{3}$. Studies are being conducted to improve the characteristics of $\mathrm{P} / \mathrm{M}$ stainless steels 
[8]. P/M stainless steels are superior to other stainless steels because of their low cost, precise size control, and better wear and corrosion resistance, which are important quality indicators [9]. Recently the wear and corrosion resistance of $\mathrm{P} / \mathrm{M}$ stainless steel parts have been improved by modifying the process parameters. The wear mechanism of P/M 316L stainless steel depends strongly on its microstructure, which is influenced by the sintering atmosphere [10]. Other studies have attempted to increase the specific mass, decrease the porosity and improve the fatigue behavior of $\mathrm{P} / \mathrm{M}$ stainless steel parts [11].

AISI 316L stainless steels have a low carbon and high nickel and chromium content. A low carbon content helps to prevent corrosion. However, this kind of steel may experience internal wear and corrosion where the stress and oxygen consumption is high [12]. Because weakness and failure of the prosthesis material will require the patient to undergo subsequent surgical operations, the material must have excellent mechanical, wear and corrosion properties [3]. In this study, the effects of sintering 316L stainless steel produced by $\mathrm{P} / \mathrm{M}$ at different temperatures on its microstructure, mechanical properties and wear behavior were investigated.

\section{Experimental}

In this study, AISI 316L stainless steel powder with a chemical composition of $\mathrm{Cr} 17.4 \%$, Ni 12.8\%, Mo 2.3\%, Mn $0.2 \%$, Si $0.8 \%, \mathrm{C} 0.08 \%$ and the balance of $\mathrm{Fe}$ was used. $\mathrm{Zn}$-Sterat $(0.6 \%)$ was added into the powder as a lubricant. Before pressing, the stainless steel powder and lubricant were mixed in a conical mixer at $22 \mathrm{r} / \mathrm{min}$ for $20 \mathrm{~min}$. A single action press with a capacity of $400 \mathrm{kN}$ was used to press the powder. Before sintering, the samples were pressed with a compacting pressure at $800 \mathrm{MPa}$ to give an initial density of $6.906 \mathrm{mg} / \mathrm{m}^{3}$. The density before pressing was the same for all of the samples. Prismatic samples were then produced by sintering the compressed samples at $1200^{\circ} \mathrm{C}$ (Group 1), $1250^{\circ} \mathrm{C}$ (Group 2), and $1300^{\circ} \mathrm{C}$ (Group 3) in an atmosphere-controlled oven under nitrogen gas.

After preparing the samples in accordance with the standard metallographic procedure, the microstructures of the investigated alloys were analyzed using a metallurgical light optical microscope (LOM, Leica DM ILM), a camera system (Leica DFC290), and a scanning electron microscope (SEM, Jeol 6060).

The mechanical properties of the steels at room temperature were determined using hardness and impact tests. The hardness of the samples was measured using the knoop indenter in a microhardness testing machine. Impact tests were conducted without a notch on four samples from each of the three different groups at room temperature. The microstructures of the fractured surfaces obtained from impact testing were analyzed by SEM.

Wear tests of the investigated steels under dry conditions were carried out using a pin-on-disc-type wear device. The samples were tested under forces of 5,10 , and $20 \mathrm{~N}$ at a sliding rate of $0.5 \mathrm{~m} / \mathrm{s}$ and a sliding distance of $2000 \mathrm{~m}$. The weights of the samples were measured before and after the experiment using electronic scales with an accuracy of 0.1 $\mathrm{mg}$, after which the results of the experiment were evaluated according to the loss in weight. The surface of the specimens was analyzed using LOM and SEM to determine the wear mechanisms of the samples.

\section{Results and discussion}

The optical microstructures of P/M 316L stainless steel implant samples sintered at 1200,1250 and $1300^{\circ} \mathrm{C}$ for $30 \mathrm{~min}$ are shown in Figure 1. The optical micrographs reveal the pore distribution and, ratio of the samples and also show the presence of powder grains. The ratio, type, shape and size of pores, and the powder grain size have important effects on the mechanical properties of materials produced using $\mathrm{P} / \mathrm{M}$.

The samples sintered at $1200^{\circ} \mathrm{C}$ contain many pores with irregular shapes and sharp edges. There are very big pores between the powder grains and the grain boundaries are indefinite. As can be expected from the microstructures of these samples, their mechanical properties are very poor because of the high porosity ratio caused by insufficient sintering. Pores with irregular shapes can also be seen in the microstructure of the samples sintered at $1250^{\circ} \mathrm{C}$. However, because the sintering temperature of this group was higher than that of the first group, the porosity ratio is lower. However, powder grain boundaries are still indefinite and grains are irregularly sized. The samples sintered at $1300^{\circ} \mathrm{C}$ possess a low porosity ratio and the pores are spherical, which significantly improves the mechanical properties of these samples. The optical microstructures of this group of samples show that sintering at $1300^{\circ} \mathrm{C}$ is acceptable in terms of grain boundaries, pore geometry and porosity ratio.

SEM micrographs of the samples are shown in Figure 2. An SEM micrographs of a sample sintered at $1200^{\circ} \mathrm{C}$ shows capillary and sharp-edged pores in the grain boundaries. This is a result of insufficient sintering, and negatively affects the mechanical properties of this group. The samples sintered at $1250^{\circ} \mathrm{C}$ contained many sharp-edged pores in the grain boundaries. As above, this is a result of insufficient sintering and decreases the strength of the material. In the SEM micrographs of a sample sintered at $1300^{\circ} \mathrm{C}$, smaller, more spherical pores were seen in the grain boundary compare with those in samples sintered at lower temperature. The higher sintering temperature improves the mechanical properties of the samples. Comparison of the SEM micrographs of the three groups of samples shows that the mechanical properties of P/M 316L stainless steel implant samples are influenced by the sintering conditions.

The microstructure and mechanical properties of $\mathrm{P} / \mathrm{M}$ 

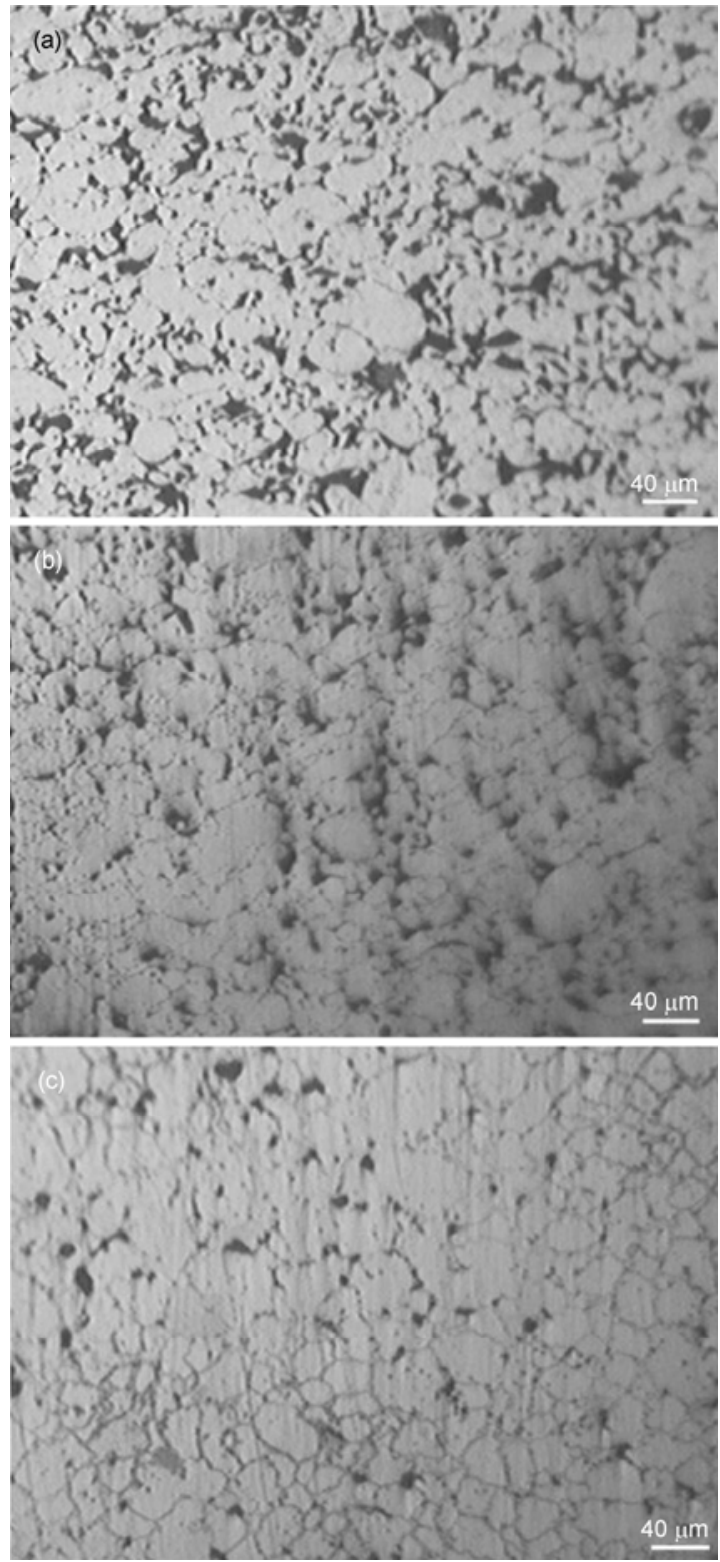

Figure 1 Optical micrographs of P/M 316L implant materials sintered at $1200^{\circ} \mathrm{C} \mathrm{(a),} 1250^{\circ} \mathrm{C}(\mathrm{b})$ and $1300^{\circ} \mathrm{C} \mathrm{(c).}$

steels can be improved by changing the sintering conditions. In addition, the sintering temperature, time and atmosphere can also be optimized to decrease the porosity ratio of materials produced by $\mathrm{P} / \mathrm{M}$. High temperature sintering can be used to eliminate small size pores, make residual pores spherical, and homogenize the steel. Spherical pores increase the tensile and fatigue strength of a sample [13]. It is known that pores are the most important factor defining the mechanical properties of $\mathrm{P} / \mathrm{M}$ steels. Decreasing porosity ratio of $\mathrm{P} / \mathrm{M}$ materials improves all its mechanical properties. The shape and size powder grains are important factors to decrease the porosity ratio of P/M materials. As a result, powder grain geometry, and sintering temperature, time and atmosphere should all be taken into account when designing
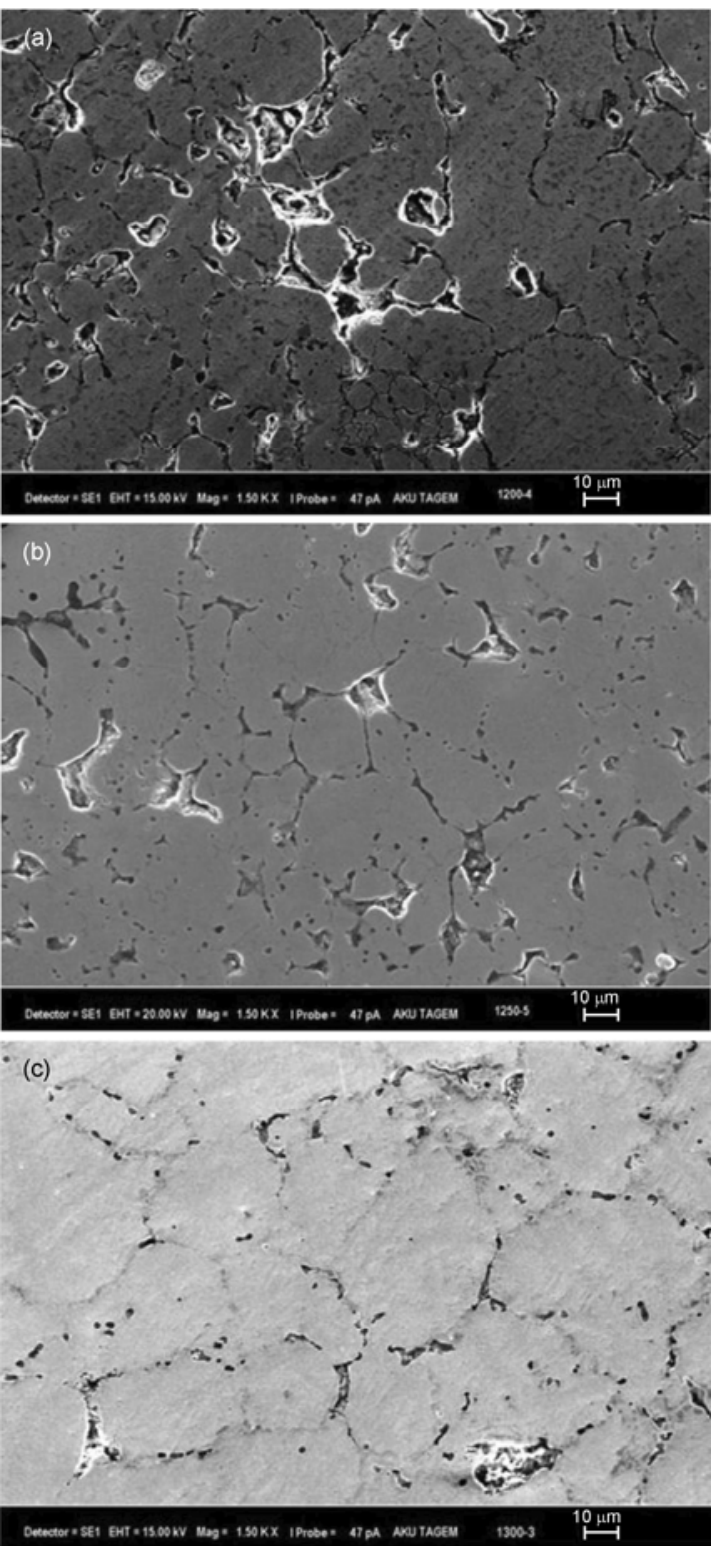

Figure 2 SEM micrographs of P/M 316L implant materials sintered at $1200^{\circ} \mathrm{C}(\mathrm{a}), 1250^{\circ} \mathrm{C}(\mathrm{b})$ and $1300^{\circ} \mathrm{C}(\mathrm{c})$.

a sintering process. The mechanical properties of $\mathrm{P} / \mathrm{M}$ materials sintered under suitable sintering conditions are significantly improved because the materials possess a low porosity ratio [13].

The hardness distributions of the three groups of samples determined by microhardness measurement are shown in Figure 3. The hardness of the three groups of samples has increased depending on the sintering temperature. In general, the samples that are sintered at $1300^{\circ} \mathrm{C}$ (3rd group) have high microhardness. A maximum microhardness of $393 \mathrm{HK}$ was obtained for this group [13]. The microhardness of ISO 5852-1 as-cast 316L stainless steel is $289 \mathrm{HK}$ [14]. The surface hardness of the samples depends on how P/M samples are compacted, powder lubrication conditions and the 


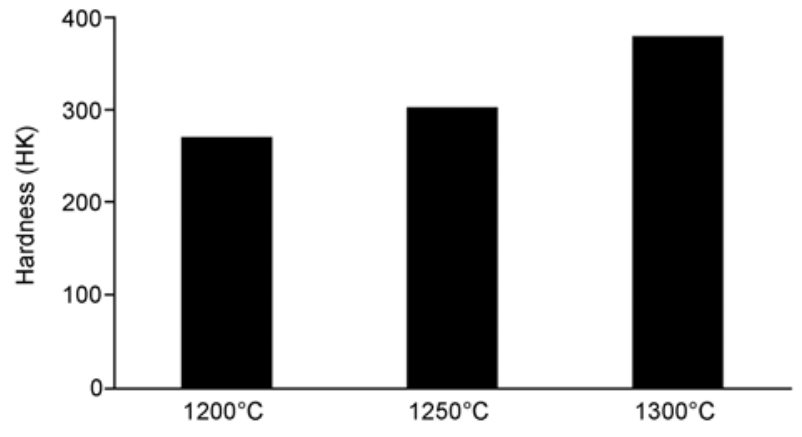

Figure 3 Hardness of steels sintered at different temperatures.

density obtained as a result of the properties of the powder [15]. The microhardness of the samples that were sintered at 1200 and $1250^{\circ} \mathrm{C}$ are lower than that of the sample sintered at $1300^{\circ} \mathrm{C}$.

The experimental results of impact testing of AISI 316L powder metal stainless steel samples sintered at 1200, 1250 and $1300^{\circ} \mathrm{C}$ are presented in Figure 4. The samples sintered at 1200 and $1250^{\circ} \mathrm{C}$ have relatively high impact energy because of their irregular pores caused by insufficient sintering. The impact energy of the samples in the group that was sintered at $1300^{\circ} \mathrm{C}$ was slightly lower. SEM images of the fractured surfaces of the test samples are shown in Figure 5.

Irregular and sharp-edged pores, and ductile fractures at the intergranular necks caused by insufficient sintering can be observed in the fractured surfaces of the samples sintered at 1200 and $1250^{\circ} \mathrm{C}$. On the other hand, the samples sintered at $1300^{\circ} \mathrm{C}$ are brittle and ductile. The impact energy of the samples in this group is slightly higher than the other samples because better sintering occurred at $1300^{\circ} \mathrm{C}$.

Figure 6 shows the variation in weight loss of the investigated steels versus load. The weight loss increased as the load and sliding distance increased. The steels sintered at $1300^{\circ} \mathrm{C}$ exhibited the highest wear resistance. Irregular shaped and sharp-edged pores were observed in the steels sintered at 1200 and $1250^{\circ} \mathrm{C}$ (Figure 1), so they were softer than the samples sintered at $1300^{\circ} \mathrm{C}$. On the other hand, because complete sintering of the steels was accomplished at $1300^{\circ} \mathrm{C}$, porosity ratio decreased and the pores became spherical. This led to improved hardness, which in turn

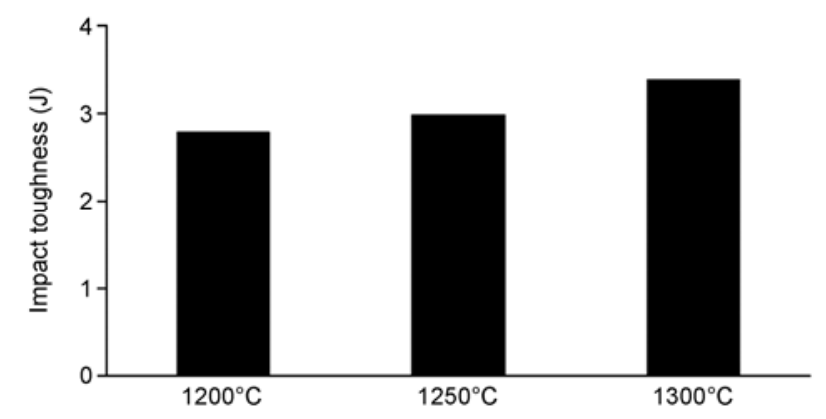

Figure 4 Impact toughness of steels sintered at different temperatures.
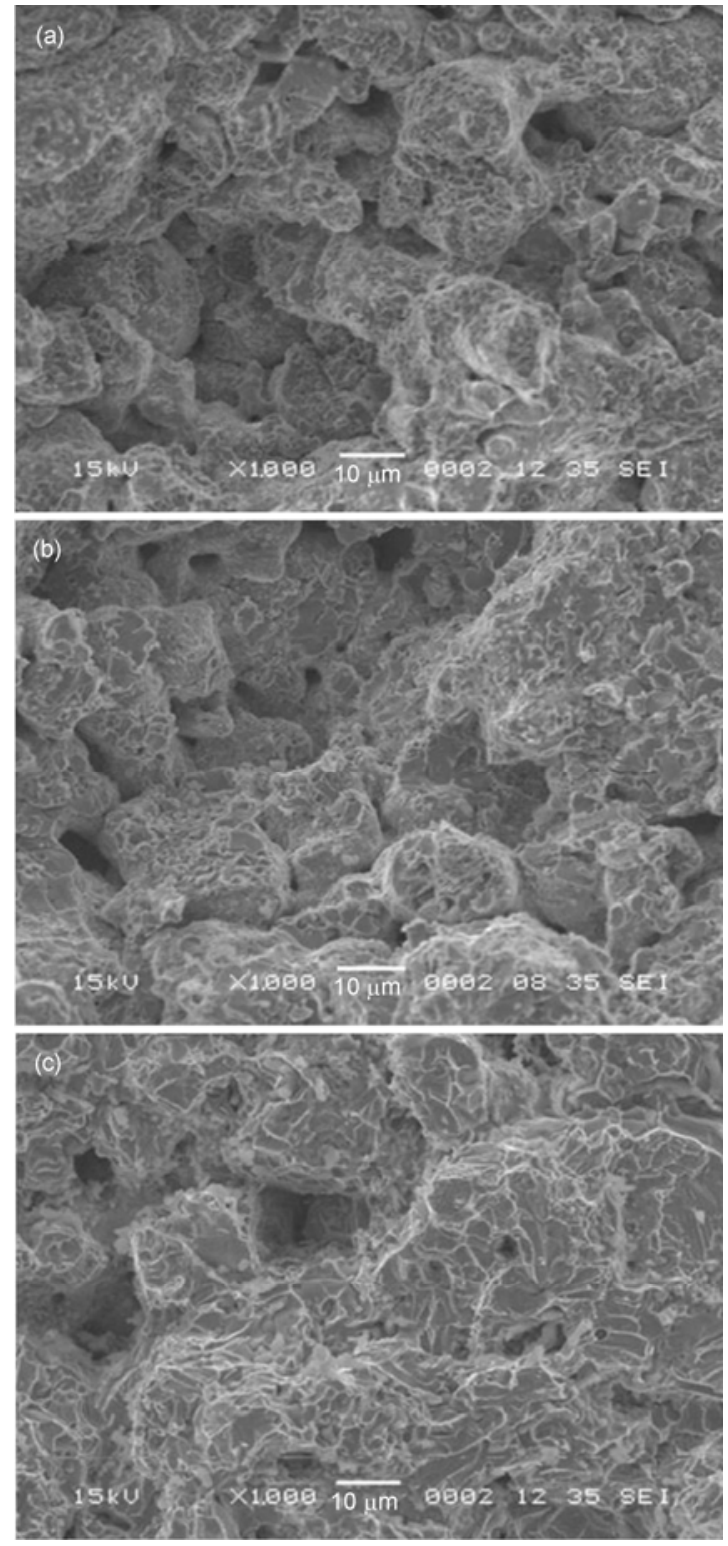

Figure 5 SEM micrographs of impact fracture surfaces of $\mathrm{P} / \mathrm{M} 316 \mathrm{~L}$ implant materials sintered at $1200^{\circ} \mathrm{C}(\mathrm{a}), 1250^{\circ} \mathrm{C}(\mathrm{b})$ and $1300^{\circ} \mathrm{C}(\mathrm{c})$.

increased the wear resistance of this group of samples.

SEM images and EDS analyses of the worn surfaces are presented in Figure 7. In the images, the wear mechanism is generally abrasive, with groove development and partial fracture. Finer grooves are present on the wear surface of the samples sintered at $1300^{\circ} \mathrm{C}$, and more oxygen peaks were seen on these worn surfaces, which means an oxide layer was present. Partial fractures were seen on the worn surfaces of the samples sintered at $1200^{\circ} \mathrm{C}$. In addition, there was a very low oxygen peak on the worn surface, so an oxide layer was not present. The lack of an oxide layer increases the contact between the surface and metal disk, which leads to increased wear of the samples sintered at $1200^{\circ} \mathrm{C}$. 

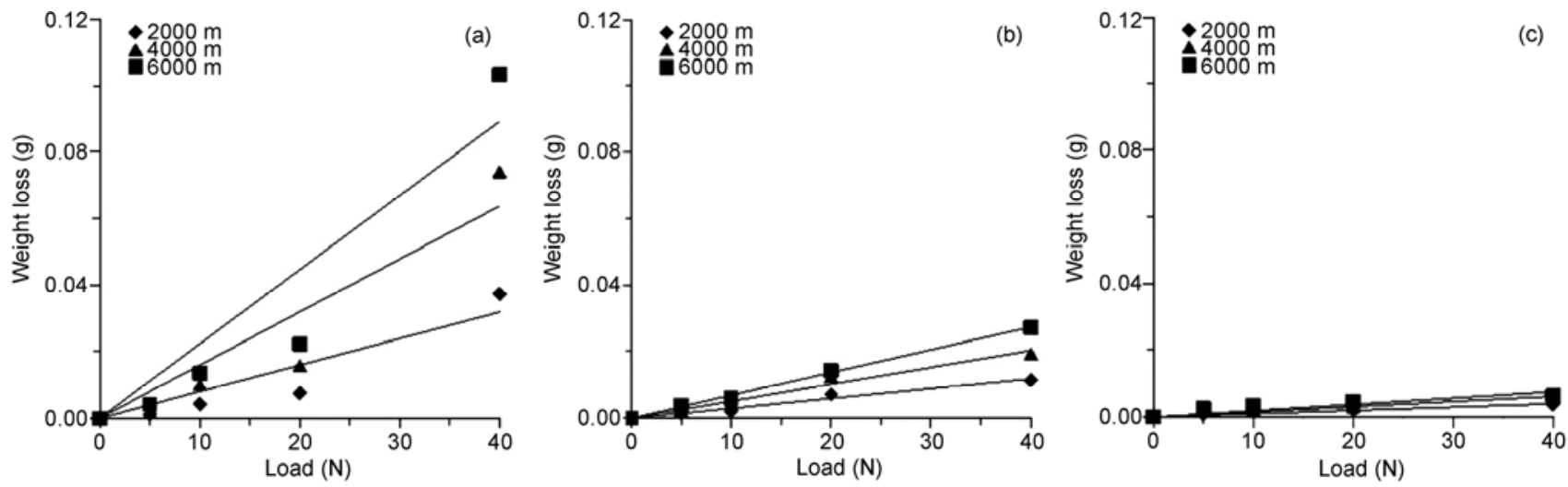

Figure 6 The relationship between weight loss and applied load for samples sintered at $1200^{\circ} \mathrm{C}(\mathrm{a}), 1250^{\circ} \mathrm{C}(\mathrm{b})$ and $1300^{\circ} \mathrm{C}(\mathrm{c})$.

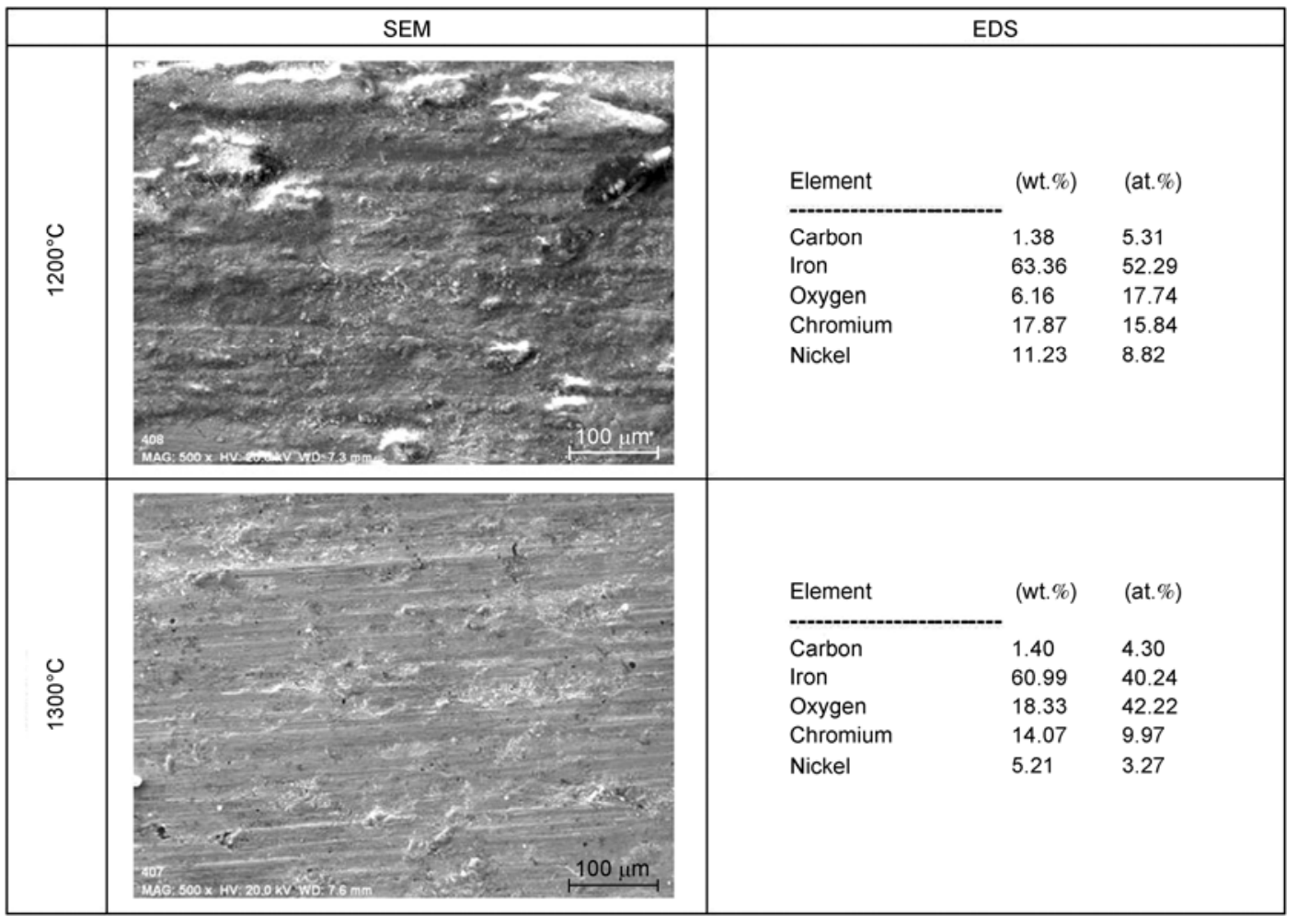

Figure 7 SEM micrographs and EDS analysis of worn surfaces.

\section{Conclusions}

Sintering temperature, time and atmosphere are important parameters affecting the porosity ratio of $\mathrm{P} / \mathrm{M}$ materials. The ratio and type of pores in a sample significantly influence the mechanical and wear properties of $\mathrm{P} / \mathrm{M}$ materials. SEM images indicate that insufficient sintering, as was found in the first and second groups of samples, resulted in low wear resistance and microhardness. In the third group of samples, use of a higher temperature resulted in better sintering, increasing wear resistance and microhardness. Comparison of the results obtained for the three groups of samples revealed that the mechanical properties of $\mathrm{P} / \mathrm{M}$ 316L stainless steel implant samples were the best for samples sintered at $1300^{\circ} \mathrm{C}$.

1 Zeren A, Zeren M, Milcan A. Mechanical properties of implants used in total hip arthroplasty. Metal World J, 2001, 98: 12-18

2 Long M, Rack H J. Titanium alloys in total joint replacement. Biomaterial, 1998, 19: 1621-1639

3 Akdoğan G, Sarıtaş S. The contribution of powder metallurgy to development of biomaterials. In: Third International P/M Conference, Gazi University, Ankara, Turkey, 2002. 1244-1262

4 Dabrowski J R, Oksiuta Z. Poros implantation material from vitalium alloy powder. Mater Eng, 2000, 4: 174-178

5 Pilliar R M. P/M Processing of surgical implants: Sintered porous 
surfaces for tissue-to-implant fixation. Int J P/M, 1998, 34: 33-45

6 Andersen P J. Medical and dental applications. J Powder Sys Appl, 1982, 657-663

7 Anonymous. Bio implant materials. Copyright Ohttp://www.directessays. com, 2002. 2-3

8 Rosso M, Grande M A. Production and characterization of P/M duplex stainless steels. In: Third International P/M Conference, Gazi University, Ankara, Turkey, 2002. 120-128

9 Coovattanachai O, Tosangthum N, Morakotjinda M, et al. Performance improvement of P/M 316L by addition of liquid phase forming powder. Mater Sci Eng A, 2007, 445-446: 440-445

10 Meng J, Loh N H, Tay B Y, et al. Tribological behavior of 316L stainless steel fabricated by micro powder injection molding. Wear,
2010, 268: 1013-1019

11 Lindstedt U, Karlsson B. Dynamic behavior of 316L stainless porous P/M steel. 1996 World Congress On P/M \& Part Mater, 1996, 5: 17-35

12 Özbek I, Konduk B A, Bindal C, et al. Characterization of borided AISI 316L stainless steel implant. Vacuum, 2002, 65: 521-525

13 Kurgan N, Varol R. Mechanical properties of P/M 316L stainless steel materials. Powder Technol, 2010, 201: 242-247

14 ISO 5832-1:1997. Implants for surgery-Metallic materials-Part 1: Wrought stainless steel. 3. Edition. Metallic Materials, 1997, 1: 9

15 Bakan I H, Heaney D, German R M. Liquid phase sintering of 316L powders in injection molded. In: Third International P/M Conference, Gazi University, Ankara, Turkey, 2002. 1179-1190

Open Access This article is distributed under the terms of the Creative Commons Attribution License which permits any use, distribution, and reproduction in any medium, provided the original author(s) and source are credited. 